\title{
CAN THERE BE GOVERNMENT HOUSE REASONS FOR ACTION?
}

\author{
Hille Paakkunainen
}

7 HIS ESSAY ARgueS that normative reasons for action are premises in good practical reasoning. In particular, reasons are considerations that L nonnormatively well-informed good deliberation takes into account, and if the reasons are decisive, it is part of good deliberation to be moved to act on them in the way that they support. Something like this claim is often quietly observed as a constraint on theorizing about reasons for action, and sometimes explicitly articulated. Mark Schroeder proposes the "Deliberative Constraint" that "one's reasons are the kinds of thing that one ought to pay attention to in deliberating," and suggests that the relative weights of two sets of reasons, $R$ and $S$, for $A$ to $\phi$ depend on which of $R$ or $S$ it is "correct to place more weight on ... in deliberation about whether to $[\phi]]^{\prime 1}$ Kieran Setiya says that reasons for $A$ to $\phi$ are premises for "sound reasoning to a desire or motivation to $\phi$," and sees this as a "harmlessly illuminating" thesis connecting "two things which surely must be connected": reasons for action and practical thinking or deliberation. ${ }^{2}$ Jonathan Way says that it is "near platitudinous" that "a reason for you to $\phi$ must be an appropriate premise for reasoning towards $\phi$-ing."

Borrowing Schroeder's term, call the general idea that reasons for action are considerations that good deliberation takes into account and, if the reasons are decisive, issues in action on, the Deliberative Constraint. This constraint is not yet a theory of reasons - at least, not in the version I will defend-but a necessary condition compatible with many further views. While the Deliberative Constraint is relatively orthodox, it has not gone unchallenged, and we currently

1 Schroeder, Slaves of the Passions, 33, 26, 130, 136-40.

2 Setiya, "What Is a Reason to Act?" 221, 223.

3 Way, "Reasons as Premises of Good Reasoning," 1. For other articulations of similar theses, see, e.g., Raz, Practical Reasoning, 5, "The Truth in Particularism," 228, and From Normativity to Responsibility, chs. 2, 5; Darwall, Impartial Reason, 30-31; Wallace, "Constructivism about Normativity," 19; and Sinclair, "Promotionalism, Motivationalism, and Reasons to Perform Physically Impossible Actions,” 649-50, 658. 
lack a good sense of why we should subscribe to it, if at all. My aim is to articulate what is right about the orthodoxy, and to explain why recent challenges to it misfire. I argue that if we abandon the Deliberative Constraint, we are left operating with a notion of reasons for action that cannot make sense of reasons' peculiar normativity, and relatedly, cannot play the usual theoretical roles that give questions about the nature and extent of our reasons for action much of their import. We can decide to operate with such a notion of reasons, of course. But we should realize what is thereby sacrificed.

Thoughts in the vicinity of the Deliberative Constraint can seem obviously true, whether explicitly articulated or implicitly adhered to. For example, Horty frames his study of reasons as a study of the logic of reasoning, assuming it as an obvious feature of everyday discourse that reasons are something to focus on in deliberation, provided we are informed of the considerations that are the reasons. ${ }^{4}$ Versions of the same assumption inform Williams's famous argument for "internalism" about reasons, Korsgaard's neo-Kantian internalist alternative, as well as many "externalist" views such as those of McDowell or FitzPatrick. ${ }^{5}$ These views disagree not on whether reasons are linked to good deliberation, but on whether the agent whose reasons they are must be motivationally capable of undertaking the relevant good deliberation (as for internalists) and, relatedly, what the relevant kind of goodness in deliberation is. ${ }^{6}$ Parfit, too, links practical normative reasons to an ideal of rational response to the considerations that are the reasons:

The rationality of our desires and acts depends on whether, in having these desires and acting in these ways, we are responding well to practical reasons or apparent reasons [i.e., to considerations that, if true, would be reasons] to have these desires and to act in these ways. ${ }^{7}$

This list of authors who assume that reasons are somehow linked to good deliberation or rational response merely scratches the surface. I do not claim that they all would, on reflection, accept the Deliberative Constraint, in the form that

4 Horty, Reasons as Defaults.

5 Williams, "Internal and External Reasons"; Korsgaard, "Skepticism about Practical Reason," The Sources of Normativity, and Self-Constitution; McDowell, "Might There Be External Reasons?”; FitzPatrick, "Robust Ethical Realism, Non-Naturalism, and Normativity."

6 See Paakkunainen, "Internalism and Externalism about Reasons," for a discussion of how the Deliberative Constraint informs much of the internalist/externalist debate. Some views labeled "internalist" deny that reasons are constrained by agents' motivational capacities: see, e.g., Smith, “Internal Reasons,” and Markovits, Moral Reason, discussed below.

7 Parfit, On What Matters, 1:114, 117. Parfit holds similar views about epistemic rationality and reasons for belief. 
I will defend. But it is common to hold theses in the vicinity, regardless of one's further views.

However, it is actually highly unobvious why the normative support relations between considerations and the actions (or action types) they support should be linked to good deliberation, or to patterns of rational response to information. Normative reasons for an action are considerations that count in favor the action, at least pro tanto. Could there not be normative reasons, $p$, for agent $A$ to $\phi$ in $C$, that are just "out there," counting in favor of A's $\phi$-ing-even decisively so-but that $A$ should not or perhaps could not take into account, or act on, no matter how well-informed and rationally excellent her deliberations? Many moral theorists hold that the facts that ultimately morally justify $\phi$-ing are often to be ignored in morally good deliberation. Bernard Williams evocatively called the utilitarian version of this view "government house utilitarianism." The image evoked is that of lack of transparency, from the point of view of ordinary agents' morally good deliberations, to the facts about utility-maximization that ultimately morally justify individual action and social policy. ${ }^{8}$ If morally good deliberation can ignore ultimate moral justifications, why could rationally excellent, well-informed deliberation not ignore normative reasons, and focus on some other considerations entirely? If there can be "government house" moral justifications, why not also "government house" reasons (GH reasons)?

By GH reasons, I mean reasons that violate the Deliberative Constraint, in whatever its best formulation. While the analogy with GH moral theory is loose, it serves to point out that, if some version of the Deliberative Constraint holds, it is not obvious why. ${ }^{9}$ Putative examples of GH reasons cast further doubt on the Deliberative Constraint. Consider this well-known case from Mark Schroeder:

Surprise Party: Nate ... hates all parties except for successful surprise parties thrown in his honor [which he loves]. Given Nate's situation, the fact that there is a surprise party waiting for him now at home is a reason for him to go home. But it isn't a reason that Nate could know about or act on. Still, someone Nate trusts might [truly] tell him that there is a reason for him to go home now. ${ }^{10}$

The thought is that, although the fact, $p$, that a surprise party awaits is a reason for Nate to go home, Nate cannot believe that $p$ without destroying $p$ 's status as a

8 Williams, "Ethics and the Limits of Philosophy," 108-10.

9 The statement of GH moral theory could also be refined, e.g., to account for how ultimate or "fundamental" moral justifications relate to "derivative" ones (Star, Knowing Better). Section 5 below addresses parallel complications regarding reasons for action. 
reason. ${ }^{11}$ (The surprise would be ruined, and ceteris paribus, Nate has no reason to go to ruined surprise parties, since he hates them.) Since taking $p$ into account in deliberation requires believing that $p, p$ is a reason for Nate only if Nate does not take $p$ into account in deliberation, and so only if Nate does not take $p$ into account in good deliberation. ${ }^{12}$

Julia Markovits suggests many further examples:

James Bond: Let's say I become convinced I am James Bond. The fact that I am suffering from such a delusion may give me an excellent reason to see a psychiatrist for treatment. But it cannot motivate me to see the psychiatrist. For if this fact could motivate me to seek help, I would no longer be convinced I was James Bond. ${ }^{13}$

Soldier in a Just War: In a war fought on humanitarian grounds, soldiers may have reason to desensitize themselves to the common humanity of the inhabitants of an enemy state so that they can more effectively fight a war whose very justification is provided by that common humanity. If they have reason to fight in the war, and fight effectively, then they ought not to be motivated to fight by that reason. ${ }^{14}$

Emergency Landing: Captain Sullenberger successfully emergency-landed an Airbus A320, which had lost all thrust in both engines ..., in the icy waters of the Hudson River, with no loss of life. [Asked] whether he had been thinking about the passengers as his plane was descending rapidly ..., Captain Sullenberger replied, "Not specifically.... I mean, I knew I had to solve this problem. I knew I had to find a way out of this

I will assume that reasons are facts or true propositions, $p$ (I will not worry about which). Following convention, I often call both "considerations." For ease of writing, I sometimes say that $A$ "has" a reason to $\phi$, meaning that there is a reason for $A$ to $\phi$. I assume that, whenever there is a reason, there is some (possibly conjunctive) consideration, $p$, that is that reason.

Ironically, Schroeder introduces the case right after articulating his "Deliberative Constraint" (Slaves of the Passions, 26). He does so to argue that existential normative facts such as "there is a reason for me to go home now" might themselves be reasons, since Nate would be deliberating well if he took this fact into account (32-33). But cf. Schroeder, Slaves of the Passions, 167.

Markovits, Moral Reason, 41. The case is from Johnson's "Internal Reasons," 575. See Smith, "Reasons with Rationalism after All," 523; Millgram, "Williams' Argument Against External Reasons"; and Sobel, “Explanation, Internalism, and Reasons for Action," for similar cases. 
box I found myself in.... My focus at that point was so intensely on the landing ... I thought of nothing else." ${ }^{15}$

In James Bond, as in Surprise Party, the agent cannot take the putative reason into account without destroying it (perhaps by destroying the fact, $p$, that was supposed to be the reason). In Soldier and Emergency Landing, the agent should not take the putative reasons into account, or be moved by them. Thus it seems that it cannot be part of good deliberation to take them into account and be moved by them, even if the reasons are decisive. ${ }^{16}$ Lest we brush such cases aside as rare exceptions, Markovits suggests further everyday examples:

A specialist ... may be able to cure more patients if she's in it for the social prestige than if she's in it chiefly to save lives.... A surgeon may operate more successfully ... if she is not thinking of the life that is at stake. [We are often fortunate to be] driven by ulterior motives, habit, instinct, or "auto-pilot" rule-following to make decisions or react to threats which we would have likely reacted to less well if we had been responding motivationally to our reasons.... If a child runs into the street right in front of my car, I hit the brakes automatically - I am not motivated by a concern for the well-being of the child. In a surprising number of cases, there is much to be said for not being motivated by our reasons. ${ }^{17}$

Such cases look to challenge the Deliberative Constraint. If the Constraint is nonetheless defensible, we should explain why these examples do not defeat it, in its best formulation.

Notice that, even if we abandon the Constraint, there are other ways of linking agents' reasons to their subjective perspectives, or to some hypothetical rational response, that the above examples do not challenge. For example, Markovits's own view (which she calls "internalism") is that a reason for $A$ to $\phi$ is a consideration that counts in favor of $A$ 's $\phi$-ing "in virtue of the relation it shows $\phi$-ing to stand in to [A's] existing ends"-for example, a causal or constitutive means-ends relation, or that of being valuable because of the value of $A$ 's ends. ${ }^{18}$ Differently, on Michael Smith's "Advice Model," there is a reason for $A$ to $\phi$ if and only if $A$ 's perfectly rational counterpart, $A+$, who is thinking about what the actual, less-than-perfectly rational $A$ should do, would desire that $A$ 
$\phi$ s. ${ }^{19}$ Crucially, $A+$ might desire that $\mathrm{A} \phi \mathrm{s}$, even if there is no good deliberative route via which $A$ might come to do $\phi$ on the basis of her normative reasons for $\phi$-ing. We should explain why it is that, even if we link agents' reasons to their subjective perspectives or to hypothetical rational responses in these other ways, we still miss out on something important if we abandon the Deliberative Constraint.

I proceed as follows. Section 1 formulates the version of the Deliberative Constraint I defend, and explains why it is relatively modest and available to many theorists. Section 2 defends the Constraint against the counterexamples above. Sections $3-5$ develop a positive argument for the Constraint, while responding to objections and introducing some qualifications. The core of the positive argument is that, despite its modesty, the Constraint captures something deeply important about reasons for action: an aspect of their relationship to agents without which we cannot make sense of reasons' peculiar normativity. We can choose to operate with a notion of reasons that abandons the Constraint, but only at the cost of failing to make sense of how reasons can fulfill certain familiar and important theoretical roles associated with their normativity. Leaving these roles behind and hewing to others, we could operate with a different reason-concept, provided we are clear that that is what we are doing. Still, the Constraint is a condition of making sense of reasons' peculiar normativity. Section 6 concludes.

\section{FORMULATING THE DELIBERATIVE CONSTRAINT}

To formulate the Deliberative Constraint, let us start with Setiya's version, revising as problems arise:

Setiya's Reasons (SR): The fact that $p$ is a reason for $A$ to $\phi$ [in circumstance $c]$ just in case $A$ has a collection of psychological states, $C$, such that the disposition to be moved to $\phi$ by $C$-and-the-belief-that $p$ [in $c$ ] is a good disposition of practical thought, and $C$ contains no false beliefs. ${ }^{20}$

Some initial clarifications: first, "practical thought" is meant inclusively. $\phi$-ing because $p$, where $p$ is a consideration on which one acts, is a limiting case of practical thought or deliberation whose premise is $p$. More complex phenomena, such as forming beliefs about which considerations, $p_{1} \ldots p_{n}$ are reasons for

19 Smith, The Moral Problem, 156-61, "Internal Reasons," and "Reasons with Rationalism After All." Smith emphasizes that his Advice Model is unthreatened by examples such as those that challenge the Deliberative Constraint ("Reasons with Rationalism after All," 523-24; cf. Sobel, "Explanation, Internalism, and Reasons for Action").

Setiya, Reasons without Rationalism, 12, and "What Is a Reason to Act?" 222. 
what, and acting on the basis of such beliefs, also count. ${ }^{21}$ Second, reasons are facts or true propositions $p$, and these are often ordinary nonnormative facts (e.g., [Bert is in pain]). It is the further fact that [the fact that $p$ has the property of being a reason] that is a normative fact. ${ }^{22}$ SR states the putative conditions under which such normative facts obtain. Third, the final clause, that $C$ contains no false beliefs, is designed to rule out cases in which otherwise impeccable reasoning that depends on false beliefs leads one to do something one intuitively has no reason to do. I would like a gin and tonic; I falsely believe that this glass contains gin when it contains petrol; and I am led by cogent means-ends reasoning to mix the contents with tonic and drink it. I have no real reason to drink the mixture. ${ }^{23}$ Normative reasons correspond only to deliberation whose course does not depend on false beliefs, and in this sense to "sound" rather than merely "valid" deliberation. ${ }^{24}$

I accept these clarifications-though I call "deliberation" what Setiya calls "practical thought" - and I defend merely a conditional claim, not a biconditional, for reasons I will explain. For now, note two problems with sR's focus on motivational dispositions.

First, sometimes we have reasons for various conflicting act options. Seeing this, Setiya suggests that, because SR is concerned with pro tanto reasons that might be overweighed, we should not connect A's reasons to A's $\phi$-ing or intending to $\phi$ as a result of good deliberation, but only to A's having a "motivation or desire" to $\phi$, as SR does. ${ }^{25}$ This is fairly plausible. When reasons to $\phi$ are overweighed by reasons to $\psi$, sound deliberation surely would not lead A to (intend to) $\phi$. But likewise, why think that good deliberation in the face of reasons for conflicting options must lead one to have a "desire or motivation"

21 Setiya, "What Is a Reason to Act?" 221. Cf. Way, "Reasons as Premises of Good Reasoning," $2-3$, on the broadness of "reasoning."

More carefully, the type of dependence on false belief to rule out is (i) dependence on false belief-contents as premises in deliberation, and (ii) distorting effects of false background assumptions on how one deliberates. Deliberation can be sound while depending on the presence of false beliefs in certain other ways. A may have reasons to rid herself of false beliefs, and can deliberate soundly about how to do so, aptly relying, in the process, on the true belief that she has false beliefs. Sound deliberation can also sometimes depend on ignorance of fact-as when one has reasons to inquire into a topic, or differently, when deciding which horse to bet on (cf. Setiya, "What Is a Reason to Act?" 224). In such cases, one's reasons are facts other than those facts about which one is ignorant or mistaken. (Among these other, reason-giving facts might be the fact that one is ignorant about $X$, or harbors erroneous beliefs about $X$.) 
for each option (presumably via the activation of corresponding motivational dispositions)? Reasons may be considerations that good deliberation somehow registers. But better to hold that good deliberation can register reasons by weighing them, at least in rough comparative terms, where this need not involve activating or engendering conflicting motivations. ${ }^{26}$ Plausibly, it is part of good deliberation to be motivated by the weightiest reasons. But motivation need only accompany the "winning" side.

Second, thinking of registering reasons in terms of weighing, instead of in motivational terms, also helps to distinguish reasons from enabling or disabling conditions. The fact, $p$, that I can keep my promise is not a reason to keep it, but an enabling condition on other facts' being reasons to keep it. ${ }^{27}$ Still, it may be good to note in deliberation that I can keep the promise (suppose I previously thought I cannot), and this may make the difference between having and lacking the (good) motivation to keep it. Setiya admits that sR counts each fact, $p$, such that the disposition to be moved to $\phi$ by $C$-and-the-belief-that- $p$ is a good disposition of practical thought, as a reason to $\phi$; and so that it cannot distinguish reasons from enablers. ${ }^{28}$ In contrast, good deliberation plausibly would not assign to enablers (or disablers) weights and valences they lack. ${ }^{29}$

One might object that it is overly intellectualized to construe good deliberation as involving thought about the comparative weights of reasons, even implicitly. Further, sometimes it takes too long to register all of our reasons pro and con all the different act options. Surely we often deliberate as well as needed while only registering the most important reasons in the situation, as when action is needed soon. ${ }^{30}$ The right response here, I think, is to accept these claims, but to accommodate them in our understanding of the Deliberative Constraint.

In response to the charge of overintellectualizing: registering the comparative weights of reasons need not involve beliefs about reasons and their weights, considered as such. It might instead be a matter of how one updates one's (conditional) preferences concerning one's act options, upon considering the reason-giving facts, $p$, along with other relevant facts such as enablers or disablers.

Doubts about "intrinsic masking" supply one reason not to ascribe conflicting motivational dispositions (Handfield and Bird, "Dispositions, Rules, and Finks"; cf. Ashwell, "Superficial Dispositionalism," and Clarke, "Opposing Powers"). But it is also unintuitive that good deliberation in the face of reasons for conflicting options must involve conflicting motives; cf. Schroeder, Slaves of the Passions, 166.

Dancy, Ethics without Principles, 38-41. In allowing disablers, the weighing conception may also have an advantage over Way's view ("Reasons as Premises of Good Reasoning," 268n25).

Sobel, review of Slaves of the Passions. 
For instance, registering a disabler-say, that in the circumstances, I cannot keep a promise I made-might leave in place a strong conditional preference for keeping my promise, should it turn out that I can keep it after all. ${ }^{31}$ Registering decisive reasons against keeping the promise (perhaps keeping it would have disastrous consequences) would remove this conditional preference in a good deliberator. The details are work for theorists of deliberation. The general idea of weighing reasons in deliberation is intuitive enough.

Relatedly, regarding the question of time: we register and act on reasons all the time, often quickly and fairly automatically. Seeing a child running onto the road, we hit the brakes, and the fact that the child ran onto the road was a reason-and a decisive one-to do so. ${ }^{32}$ Such quick responses can be cases of acting on reasons, and so of "deliberation" in the broad sense identified above. (Compare the fastness and automaticity of most inferences involved in everyday conversations, or in simple arithmetic.) Indeed, it is part of the point of training in a complex activity that one's skilled, trained responses become fairly fast and automatic, while remaining intelligent, rational responses to key reason-giving features of situations. We need not in any case claim that every case of good deliberation involves responding to all of one's reasons. Rather, whenever $p$ is a reason for or against $A$ 's $\phi$-ing in circumstance $C$, there is a possible course of good deliberation in $C$ that does involve $A$ 's assigning to $p$ the (comparative) strength, $s$, and valence, $v$, that $p$ has in $C$. This leaves room for instances of good deliberation that are more truncated.

This last formulation is roughly correct, but let us explicitly forestall two confusions. First, it often is not good deliberation to respond to only one or few of the reasons in a situation, especially if the reasons responded to are insignificant while the reasons ignored are weighty. Suppose that if I marry Fred I will be a dollar richer than if I marry Frida, and suppose that this fact is a reason, albeit a very insignificant one, to marry Fred rather than Frida. I am aware of other relevant facts that are weighty reasons for or against marrying either, but I ignore those in my decision-making, making my decision solely based on the extra dollar. This would not plausibly be good deliberation. There are limits to how truncated good deliberation can be. Good deliberation in a situation cannot focus exclusively on insignificant reasons while ignoring significant ones. This does

This need not involve having an unconditional motivation or desire toward keeping the promise.

What about the fact that the child's well-being is at stake-a fact we might have no time to register? (Markovits, Moral Reason, 48-49) This raises the question of which of many nearby facts to count as "the" reason or reasons; as well as which reasons are "fundamental" and which ones are "derivative." Section 5 discusses these issues. 
not conflict with the formulation above, but it is worth making explicit. Well-informed good deliberation should at least register all of the important reasons in the situation, lest it lead one astray from what the balance of reasons supports.

Second, and related, we should explicitly rule out the following possibility: that although there is, for each (important) reason $p$, some possible course of deliberating well in $C$ that assigns to $p$ the (comparative) strength and valence that $p$ has in $C$, there is no single possible course of deliberating well that takes into account all of the important reasons, $p_{1} \ldots p_{n}$ in C. Again, well-informed good deliberation should intuitively respond to all of the important reasons in the situation, lest it lead the agent astray from what the balance of her reasons supports.

Incorporating these points, and henceforth restricting our attention to important (in the sense of relatively weighty in the context) reasons, here is a revised version of the Deliberative Constraint:

Reasons Revised (RR): The fact that $p$ is a reason of strength $s$ for $A$ to $\phi$ in $C$ only if there is a course of deliberating well tout court such that $A$ could undertake it in $C$, therein taking $p$ into account (along with other relevant facts such as further reasons, enablers, and disablers) and weighting $p$ 's strength as $s$-where her so weighting $p$ depends on no false beliefs. Deliberating well concludes either in acting on the weightiest reasons, in the way that they support, or in forming an intention to so act, or, if no set of reasons is weightiest, in true belief about which actions are the permitted or best options. ${ }^{33}$

With some qualifications introduced in section 5 , RR is the version of the Deliberative Constraint I defend. If RR holds, then at least our important reasons cannot be GH reasons. And it is unclear why we should posit the existence of GH reasons at all, if they are doomed to unimportance as normative phenomena. ${ }^{34}$

Four final clarifications before arguing for RR. First, RR is proposed as a conceptual truth about reasons. But if RR is true and our concept of a reason is not erroneous, our metaphysical views about the nature of reasons and of good deliberation should respect the link that RR records. ${ }^{35}$

Three quick notes: (1) Strictly, RR also concerns reasons against, which are to be taken into account and weighted. For simplicity, the formulation omits reference to these (and to valences), speaking only of reasons for. (2) I clarify below the sense in which RR requires that $A$ "could" undertake the relevant course of good deliberation. (3) When is no set of reasons weightiest? E.g., when one's reasons are incommensurable, equally good, or "on a par” (Chang, "Introduction”).

Recall that reasons can be conjunctive facts. If many insignificant reasons together constitute an important reason, then RR applies to it. 
However, second, many different views could respect the proposed conceptual truth. RR links reasons not to deliberation that is good in some qualified sense (instrumentally, morally, prudentially), but to deliberation that is good tout court, without qualification. RR does not say what such deliberation is like, aside from involving weighting reasons in accord with their actual strengths, and acting on the weightiest reasons. Deliberation that is good tout court may also turn out to be, say, instrumentally or morally good, but RR does not say so. Further, RR is silent on whether reasons' status and weight as reasons is grounded in their status as premises in good deliberation, or vice versa-or neither.

Third, on the idea of deliberating well tout court: I said this involves weighting reasons in accord with their actual strengths. The idea of deliberating well tout court therefore makes reference to the concept of a normative reason. Does this make RR either trivial and unhelpful, or objectionably circular? No: circularity is a problem for views with reductive ambitions. RR is offered as a conceptual truth, but not as a reductive definition of the concept of reasons for action in terms of the concept of deliberating well tout court. The two concepts can be interconnected yet irreducible to one another. ${ }^{36}$ Nor is RR trivial. As noted (in the introduction), we can reasonably doubt whether normative support relations between reasons and actions are necessarily linked to rational responses to the reason-giving facts. And we can raise putative counterexamples. Even if the idea of deliberating well tout court is the idea of rationally responding to, and acting on, normative reasons, RR may be false: there may be reasons for which no course of deliberating well tout court, in the relevant sense, is available. ${ }^{37}$

Finally, a clarification about the sense in which RR requires that $A$ "could" undertake a course of good deliberation that takes accurate account of her reasons. RR does not assume that $A$ has the present actual motivational capacity to do so. The closest worlds in which $A$ undergoes such a course of deliberation may be ones in which $A$ acquires the motivational capacity to do so-perhaps by acquiring dispositions she actually lacks. This is not to say that $A$ might have no capacity for deliberation, and yet have reasons for action. Plausibly, only minimally rational agents - agents capable of acting on the basis of considerations, and so of "deliberating" in the broad sense introduced—can have normative reasons for action. But RR leaves it open that $A$ can have reasons while lacking the capacity

of reasons.

36 Familiarly, however, conceptual irreducibility leaves room for ontological reducibility (cf. Schroeder, "Realism and Reduction," and Slaves of the Passions, ch. 4).

37 If there were generally no such thing as responding rationally to, and acting on, the reason-giving facts, we might conclude that there is no philosophically interesting concept of deliberating well tout court to be had. But this conclusion would be wildly premature here. 
to go through the specific deliberative routes to which her reasons correspond. $A$ 's deliberating well in the relevant way need not be motivationally possible for $A$, but only metaphysically possible, holding fixed facts about the nature of deliberation, about $A$ 's being a minimally rational agent, and about what deliberating well in circumstance $C$ is like. ${ }^{38}$

RR thus does not presuppose "internalism" about reasons, understood as the view that necessarily, if $p$ is a reason for $A$ to $\phi$ in $C$, then $A$ is capable of being motivated to $\phi$ by the belief that $p$ (together with whatever else-e.g., preexisting desires-is needed for such motivation). ${ }^{39}$ Still, RR also leaves it open that such internalism is a further necessary condition on reasons. I formulate RR as a conditional claim, not a biconditional, to preserve its modesty in this regard. While I only argue for RR - thus securing the claim that reasons are premises in good deliberation-section 4 briefly considers whether my argument might extend to support internalism.

$\mathrm{RR}$ is a version of the Deliberative Constraint that is relatively modest and compatible with many different views, yet unobvious and nontrivial. ${ }^{40}$ Why believe it-especially given the seeming examples of GH reasons in the introduction? Section 2 defends RR against these examples. In each case, the examples are naturally interpretable as consistent with RR, and the motivations for an anti-RR interpretation are at least as theoretically contentious as RR itself. Sections 3-5 then mount a positive argument for RR, giving a principled reason for interpreting the seeming counterexamples in an RR-friendly way.

\section{THE COUNTEREXAMPLES}

Recall Surprise Party. The fact that a surprise party awaits at home is supposed to be a reason for Nate to go home, but it is a fact that Nate cannot believe without destroying its status as a reason. So, the thought goes, it is a reason that Nate cannot take into account in good deliberation. Mutatis mutandis for James Bond. What to say about these putative counterexamples to RR $?^{41}$

It is in fact unobvious precisely what normative or evaluative phenomena

38 It is of course a good question what contingencies of $A$ 's psychology may be part of "C." Cf. note 46 below.

Paakkunainen, "Internalism and Externalism about Reasons," discusses this and other versions of internalism. See also the essays in Setiya and Paakkunainen, Internal Reasons; and Lord and Plunkett, "Reasons Internalism."

40 RR is also neutral on "particularism" about reasons à la Dancy, Ethics without Principles.

41 Traditional "conditional fallacy" examples (Johnson, "Internal Reasons and the Conditional Fallacy") do not threaten RR. RR allows that one's being a generally bad deliberator can itself be a reason, e.g., to improve one's deliberative skills. Satisfying the right-hand side of 
our intuitions are tracking in such cases. ${ }^{42}$ In Surprise Party, perhaps the fact that a surprise party awaits is a reason for Nate to be glad if he ends up getting surprised: a reason for an affective response, should a pleasant outcome occur. Or it might be an explanatory reason: a fact that explains why, say, Nate's going home would be a favorable outcome from the perspective of Nate's preference-satisfaction; or why Nate's going home would be good, or good for him. Or it might be a normative reason for Nate's friends to urge Nate to go. Further, the fact that Nate would be glad if he went, or that it would be good for him, might itself be a normative reason for Nate to go, a reason that Nate can take into account and act on: RR does not conflict with these claims. Various possible distinct evaluative and normative phenomena are in the vicinity and, further, various candidate facts that might be normative reasons for Nate to go, besides the specific fact that a surprise party awaits. It is unclear that our intuitions in the case track the existence of this specific normative reason for Nate to go home, rather than (or as well as) some of these other normative or evaluative phenomena. Likewise for James Bond.

Accordingly, I doubt that such examples are decisive on their own, even if multiplied. Whether our intuitions in these cases track the existence of GH reasons for action instead of (or as well as) other evaluative or normative phenomena is partly to be decided on theoretical grounds: on grounds of whether, e.g., an agent's reasons for action are a function of her preference-satisfaction and, if so, what kind of function. Such theoretical commitments are at least as contentious as RR.

Of course, we will want a positive argument for RR, and so for interpreting our intuitions in these cases compatibly with it. Sections 3-5 give such an argument, returning in due course to reconsider Surprise Party-style cases. For now, what about cases such as Soldier and Emergency Landing? In Soldier, the soldier's putative reason to fight is the fact that the enemy inhabitants share a common humanity, but she should not think about this fact or be moved by it in the midst of fighting, lest she lose her nerve and fight (perhaps dangerously) ineffectively. In Emergency Landing, Sullenberger supposedly should not think about the fact that lives are at stake as he is landing the plane, although this fact is a decisive reason to attempt emergency landing. Do these cases challenge RR?

I doubt it. In Soldier, the common humanity of the enemy state's inhabitants

RR does not guarantee that one is already a generally good deliberator, so does not eliminate the reason. Cf. Setiya, "Introduction," 13-15.

Cf. Sinclair, "Promotionalism, Motivationalism, and Reasons to Perform Physically Impossible Actions," 657-58, and "On the Connection between Normative Reasons and the Possibility of Acting for those Reasons," 1214-16; as well as Setiya, "Reply to Bratman and Smith," 538, and "What Is a Reason to Act?" $267 n 14$. 
may be only a reason to enter or join the war, not a reason to perform this combat maneuver as opposed to that. Likewise, in Emergency Landing, the lives at stake may only provide a decisive reason to attempt emergency landing, not to perform this flight maneuver as opposed to that. It would intuitively be good deliberation for the soldier to enter the war, or for Sullenberger to attempt an emergency landing, based on the reasons for doing so. But plausibly, when already in the midst of fighting a just war, or of attempting an emergency landing, one should not anymore focus on these initial reasons, but rather on facts relevant to which specific maneuvers to perform. This is not a problem for RR: RR links reasons in circumstance $C$ to good deliberation in $C$, and the circumstance of being about to enter a just war differs from that of being in the midst of fighting one. Further, where the common humanity of the enemy inhabitants is relevant to which combat maneuvers to perform - as it surely can be, lest one risk brutalizing those inhabitants - intuitively it would be good deliberation for the soldier to consider it in her decision-making. ${ }^{43}$ In general, it would intuitively be good deliberation to choose specific combat or flight maneuvers based on the reasons for those maneuvers, rather than on the basis of some other considerations (say, about today's crossword puzzle) that do nothing to justify those maneuvers. Indeed, it is unclear why we should expect agents to choose the right maneuvers without taking into account the reasons for those maneuvers, or by taking into account some other facts entirely. ${ }^{44}$

Finally, recall that responding to reasons is often fairly quick and automatic, especially in seasoned performers of an activity. Taking account of relevant reasons even in the midst of complex activity need not excessively distract, nor be the object of unnerved attention. Some may get unnerved if they think about the relevant reasons. But we need not say that it is part of good deliberation for this to happen. It is only if one's decisions issue from bad deliberation or nonrational influence, such as being unnerved or losing focus, rather than from responding rationally to reasons in the ways that they support, that one's belief in the reason-giving facts will likely cause one to perform maneuvers one should not perform. The fact that one could get unnerved is no reason to doubt RR. ${ }^{45}$

43 Markovits admits to such a risk in Moral Reason, 47n24.

44 The soldier's normative reasons for performing a maneuver may include the fact that she was commanded to do so: the soldier's reasons need not coincide with her superiors' reasons for commanding these maneuvers. I leave aside these (first-order normative) complications here.

45 Compare: it is no part of Williams's ("Internal and External Reasons") "internalism” to deny that agents might fail, through getting unnerved, to go through the good deliberative routes to which their reasons correspond. The above points also account for the further everyday examples Markovits proposes in Moral Reason, 48-49. 
The foregoing raises two general points worth spelling out explicitly. The first concerns so-called "nonbasic" actions, their nature as processes that unfold over time, and concurrent deliberation as a mechanism of rational control over the process. (Nonbasic actions are actions done by doing something else: e.g., landing a plane, by performing certain maneuvers.) While section 1 did not discuss this possibility, RR allows that, even as A's deliberation concludes in her initiating some action, A may keep deliberating further about how, precisely, to carry out the action. We just need to understand RR as applying at different levels-to the whole action (e.g., landing the plane) and the decision to perform it, and again to parts of the whole, and the decisions to perform those parts, as the situation evolves. When a complex, skilled performance is in progress, we quickly and fairly automatically choose subactions as ways of performing the whole, rapidly adjusting our performance to the circumstance in an exercise of continuous rational control over our behavior.

The second point concerns rational versus nonrational responses to reason-giving facts, and whether it is sometimes better if agents do not deliberate in light of those facts. As noted, the possibility of getting unnerved if one considers the reason-giving facts does not tell against RR. But suppose one is very likely to get unnerved, and very unlikely to respond to one's reasons rationally. Perhaps it is better here not to deliberate at all, or to only consider some other facts. However, we need not deny that it may be in some sense better if some agents do not deliberate in some circumstances, or do not take into account reason-giving facts. Even if it would not be good to deliberate, or good to deliberate on the basis of the reason-giving facts, because one is unlikely to respond rationally to them, it can still be a case of deliberating well to respond to the reason-giving facts in the way that they support. ${ }^{46}$

In sum, Soldier and Emergency Landing do not defeat RR either. They are plausibly interpreted in line with RR. In each case, it is intuitively a case of good delib-

Perhaps you may even have decisive reasons not to deliberate (suppose an evil demon says she will destroy the world if you do). Still, if you also have decisive reasons for something else, $\phi$, besides refraining from deliberating, then there is a possible course of good deliberation-that you have decisive reasons not to undertake! - that takes your reasons to $\phi$ into account and leads you to $\phi$. Thanks to André Gallois for pressing me on this. Note that sometimes A's psychological frailties affect not (just) A's likelihood of undergoing the good deliberative routes to which $A$ 's reasons correspond, but $A$ 's reasons themselves-perhaps by affecting the circumstance in which certain facts are reasons for $A$. (Cf. the sore loser example discussed in Smith, "Internal Reasons.") I doubt there is a good general formula for when psychic frailties affect $A$ 's reasons, by affecting the circumstance, and when they affect only A's likelihood of abiding by her reasons. 
eration to respond to the reason-giving facts by acting on them, in the way they support. Still, what principled argument is there for RR?

\section{THE DISTINCTIVE POINT OF APPEALS TO REASONS FOR ACTION}

In responding to Surprise Party-style cases, I observed that they may involve various different normative or evaluative phenomena, and it is unclear why we should interpret our intuitions as indicating the presence of the specific putative $\mathrm{GH}$ reason, rather than in some other, RR-friendly way. Of course, opponents of RR can try stipulating that the GH reasons are present. But stipulations can fail. To make progress, we should consider what is distinctive about normative reasons for action, as compared to other normative or evaluative phenomena, such that we should interpret our intuitions in these cases one way rather than another. What is the distinctive point of appeals to reasons for action?

"Normative reason for action" is to some extent a term of art. We can use it as we wish, if we are clear about how we are using it. But there are key theoretical roles that the concept of reasons for action is often asked to play-roles associated with the peculiar normative importance of reasons. My argument for RR will be that if we deny it—or whatever exactly is the best version of the Deliberative Constraint-then we are left operating with a concept of reasons for action that cannot play these roles. We may choose to operate with such a concept. But we should be clear about what is thereby sacrificed. Further, the concept of reasons that can play the roles in question is clearly worth theorizing about, and in terms of. It is this concept of reasons of which, I claim, RR holds.

Which theoretical roles are in question? The first is reasons' role in prosecuting questions about what is often called "normative authority" or "robust normativity." All norms, including rules of games or clubs, have "norm-relative" normativity: one can behave better or worse by their lights. ${ }^{47}$ But some norms matter more than others. Some have genuine authority over (all or some of) us, others do not. And questions about normative authority seem to be, at least partly, questions about reasons for action. For instance, morality's authority on $A$ is usually taken to depend on whether $A$ has any (reasonably weighty) reason to do what morality requires. ${ }^{48}$ If no one had any reason to do what morality requires,

"Norm-relative normativity" is Finlay's term ("Recent Work on Normativity," 332). McPherson ("Against Quietist Normative Realism," 232-33) calls it "formal normativity," in contrast to "robust normativity" or "authority." Copp ("Moral Naturalism and Three Grades of Normativity," 255-58) calls it "generic normativity."

48 It is also usually supposed that morality is categorically authoritative only if everyone regardless of their contingent desires has reasons to be moral. For versions of the view that 
nor to avoid what is morally prohibited, then it seems that moral requirements and prohibitions would not really matter, would not have genuine authority over us. On the other hand, insofar as $A$ does have (reasonably weighty) reasons to do what is morally required, moral requirements have genuine authority over $A .^{49}$ Mutatis mutandis for other norms, such as norms of etiquette or laws. In sum, the following is part of what philosophers usually mean by "normative authority" (as a property of norms or standards, not of individuals or institutions):

Reasons Centrism: Any given norm $N$ is authoritative on agent $A$ if and only if $A$ has some (reasonably weighty) normative reason to do what $N$ says that it would be, in some sense, proper or called for (e.g., morally required, required by etiquette or law) for $A$ to do.

Nor is this mere philosophers' fiction. It is a regimentation rooted in common human concerns expressed in questions such as "Why be moral?" or "Why obey the rules?"

Reasons Centrism is fairly modest. It does not entail Reasons Basicness, the view that the property of being a reason is not analyzable in terms of other normative or evaluative properties, and is what all other normative or evaluative properties are analyzable in terms of. ${ }^{50}$ Further, both Reasons Centrism and Reasons Basicness are silent on whether the property of being a reason is reducible to something nonnormative or nonevaluative, and on whether it is a natural or a nonnatural property. ${ }^{51}$

Still, Reasons Centrism is a central organizing assumption of much contem-

everyone has such reasons, see, e.g., Shafer-Landau, "A Defence of Categorical Reasons"; Korsgaard, The Sources of Normativity and Self-Constitution; and Foot, Natural Goodness.

This authority might be merely hypothetical, if the reasons depend on A's contingent desires.

50 See, e.g., Schroeder, Slaves of the Passions, ch. 4; and Skorupski, The Domain of Reasons, for Reasons Basicness.

51 See, e.g., Scanlon, Being Realistic about Reasons; Parfit, On What Matters, vols. 1-2; and Enoch, Taking Morality Seriously, for nonreductive views, and Schroeder, Slaves of the Passions, for a reductive view. The questions of reducibility and naturalism are distinct, if there is room for nonreductive naturalism à la Sturgeon, "Ethical Naturalism." Note also that Reasons Centrism does not entail that morality's authority depends on nonmoral reasons to be moral. The relevant reasons might be moral reasons, whatever this amounts to. Thanks to Oliver Sensen for discussion. These issues are complicated partly by the fact that we can define normatively insignificant senses of "normative reason," distinct from "genuinely and robustly normative reasons," as e.g. Copp does in "Toward a Pluralist and Teleological Theory of Normativity." In one sense, any norm $N$ gives rise to "reasons" $-N$-relative reasons. I avoid these complications here: talk of normative reasons in the text always refers to genuinely and robustly normative reasons. 
porary theorizing in the area. ${ }^{52}$ Reasons Centrism underlies the point of formulating debates about the extent of morality's authority in terms of reasons for action..$^{53}$ Relatedly, Reasons Centrism is part of what makes subjectivist views, on which reasons depend on agents' contingent desires, prima facie troubling. For given Reasons Centrism and subjectivism, moral requirements have authority for $A$ only if $A$ has a suitable contingent desire, and in this sense only hypothetically. Without Reasons Centrism, it is unclear why it would make good sense to prosecute questions about morality's authority in terms of reasons for action, or to worry about subjectivism's implications for morality's authority, as is usually done.

The second, related theoretical role for reasons for action is their link to what one ought to do, in what is sometimes called a "robustly normative" sense. Unlike merely qualified oughts, such as ought-according-to-etiquette, or ought-according-to-the-laws-of-England, it is usually assumed that robustly normative oughts, just as such, bear an important link to reasons. ${ }^{54}$ Specifically, it is often assumed that, if $A$ has decisive reasons to $\phi$, then $A$ ought in the robustly normative sense to $\phi$. Further, it is important that such "oughts" can have the force of authoritative demands on agents to $\phi$, not mere recommendations. We are often interested in whether we would be violating an important, authoritative demand on us if we failed to $\phi$ (e.g., "Must I do what morality requires in this instance, given the cost to myself?"), not just in whether there is some normative support for $\phi$-ing, though it is still entirely normatively optional to $\phi$. Of course, perhaps not all reasons impose demands: perhaps some merely entice or recommend (enticing reasons), or merely justify doing something that one would otherwise have been required to avoid (justifying reasons). ${ }^{55}$ Still, the idea that (some) reasons can impose authoritative demands surely accounts for much of the theoretical interest in the notion of reasons for action. Merely "justifying" reasons would not be of much interest on their own, if there were no potential authoritative demands for them to oppose or disarm. And merely "enticing" rea-

One might still deny it, of course. Some of Kate Manne's work ("Internalism about Reasons" 113-16) may push in this direction.

It also underlies the point of asking "constitutivists" about practical reasons what reason we have to abide by agency's constitutive standards: this is a way of asking about these standards' authority or normative importance (Enoch, "Agency, Shmagency").

54 See, e.g., Broome, Rationality through Reasoning; McPherson, "Against Quietist Normative Realism.” I remain neutral on whether "ought" in English is semantically ambiguous, or univocal but picks out different norms in different contexts of use.

55 See Gert, "Requiring and Justifying"; Portmore, Commonsense Consequentialism, ch. 5; Dancy, Ethics without Principles, 21. 
sons are not very important as normative phenomena, since even the strongest and unopposed enticing reasons to $\phi$ leave $\phi$-ing entirely normatively optional.

In sum, part of the distinctive point of appeals to reasons for action is captured by Reasons Centrism, along with the related idea that decisive reasons can impose authoritative demands. My argument for RR will be that, unless reasons are linked to good deliberation à la RR, they cannot impose authoritative demands on the agents whose reasons they putatively are. $\mathrm{RR}$ is a condition of reasons' playing the roles indicated. Sections 4-5 develop this argument and respond to objections.

\section{REASONS, DELIBERATION, AUTHORITATIVE \\ DEMANDS, AND REASONABLE EXPECTATIONS}

Suppose RR is false. ${ }^{56}$ Then there might be decisive reasons for $A$ to $\phi$ in a situation, imposing an authoritative demand on $A$ to $\phi$, although there is no good deliberative route that $\mathrm{A}$ could take in that situation that would lead her from considering the reason-giving and other relevant facts to $\phi$-ing. For instance, Sullenberger might be under an authoritative demand to steer left, given facts about the plane's behavior and what it takes to land safely, but there might be no possible rational response to these facts that would lead Sullenberger to steer left on their basis. Sullenberger might still end up steering left, of course. Perhaps he happens to do so for no (motivating) reason, or via some lucky nonrational response to considering the reason-giving facts (perhaps considering them causes his arms to twitch so as to steer left at the ideal moment). Or perhaps he is somehow led to steer left via considering some other facts entirely-say, about today's crossword puzzle - that do nothing to favor this maneuver. Still, if we deny RR, we deny that there is a recognizably rational response to the reason-giving facts of the situation that Sullenberger could have, that would take him from considering those facts to doing what they demand.

This is certainly prima facie odd. ${ }^{57}$ We usually think there is a point to trying to figure out facts relevant to what we should do, and to trying to make important decisions in their light, instead of ignoring them. Likewise, we usually assume we will make better decisions if we consider the reason-giving facts ra-

The argument of this section draws in part on earlier attempts to articulate essentially the same argument in Paakkunainen, "Internalism and Externalism about Reasons" and "Normativity and Agency." complete information could lead us astray from what we ought to do" (Slaves of the Passions, 132). 
tionally; thus we try to ensure we are not intoxicated, exhausted, or otherwise incapacitated when we have to make important decisions. In sum, we often seem to tacitly assume that deliberating well in light of the reason-giving facts helps us to do what we ought. Still, what exactly rules out the prima facie odd possibility that, at least sometimes, there is simply no way for us to rationally respond to the reason-giving facts by taking account of and acting on them, in the way they demand?

What rules it out is a further conceptual connection between authoritative demands and reasonable expectations. If the facts in a circumstance impose an authoritative demand on $A$ to $\phi$, then it must be reasonable to expect of $A$ that she $\phi$, at least under some conditions. More carefully, if some facts, $p$, demand of $A$ that she $\phi$ in $C$, then there must be some possible condition $X$ that $A$ might be in in $C$, such that if $A$ encounters $C$ while in condition $X$, then it is reasonable to expect of $A$ that she will $\phi$. The operative notion of reasonable expectations is partly predictive, partly normative.

The predictive part is that, if $A$ is in condition $X$ in $C$, then $A$ will $\phi$ in $C$; moreover, it is predictable that the action, $\phi$, that $X$ leads $A$ to do is precisely the reason-demanded action. That is, there is a predictable match between what the reasons, $p$, demand of $A$, and what $X$ leads $A$ to do: condition $X$ well-equips $A$ to do, in $C$, just what the reasons demand. Unless there is some such possible condition $X$, the idea that the reasons can authoritatively demand $A$ to $\phi$ seems to lapse. Again, $A$ might of course happen, by sheer accident, to do precisely $\phi$. And we might think of this accident as a happy one, applying some positive evaluative predicate to it. ${ }^{58}$ But $\phi$-ing is not something that reasons can authoritatively demand of $A$, if there is no possible condition, $X$, that well-equips $A$ to meet those demands. So it seems to me.

What kind of condition might $X$ be, then? Here the normative dimension of the operative notion of reasonable expectations is relevant. Reasons cannot impose demands on $A$ to $\phi$ that it is completely unreasonable to expect of $A$ that she fulfill. Reasons can sometimes demand difficult things of us-whether psychologically or physically difficult. But crucially, failures to do the reason-de-

58 Compare Railton, "How Thinking about Character and Utilitarianism Might Lead to Rethinking the Character of Utilitarianism," 408-10, on "morally fortunate" actions. Railton proposes "valoric utilitarianism" as a theory of "moral rightness" conceived of as classifying actions as morally fortunate or unfortunate. Rightness thus conceived may lack commonsense links between rightness and obligation on the one hand, and blameworthiness and what can be reasonably expected of people on the other. Railton acknowledges that such a theory risks being a mere classificatory scheme, and needs to explain why its notion of rightness still answers to concerns that make moral rightness an important notion to theorize in the first place. 
manded thing, whether difficult or not, must be apt targets of criticism - at least absent excusing conditions. ${ }^{59}$ Unless such failures are apt targets of criticism, the putative demand or expectation to $\phi$ lapses as wholly unreasonable. This dimension of apt criticizability will help us to determine the kind of condition that the well-equipping condition, $X$, must be.

When are putative demands wholly unreasonable and so not really in place, and when are they reasonable but such that $A$ is excused for failing to meet them? Plausibly, nonculpable ignorance of relevant nonnormative facts, such as the reason-giving facts, $p$, excuses, while leaving the reasons and associated demands in place. ${ }^{60}$ It is controversial what further conditions excuse. Extreme physical or psychological difficulty in meeting a demand plausibly excuses, at least sometimes. (Suppose one has post-traumatic stress disorder, or was drugged against one's will. On the other hand, when mere viciousness makes doing good things hard, perhaps one is not excused). Perhaps, at the limit, physical or psychological impossibility makes would-be demands lapse entirely: plausibly, reasons simply cannot demand us to fly unaided to the moon, for example. ${ }^{61}$ I return to psychological impossibility below. For now, focus on the claim, above, that when there is no condition, $X$, that $A$ could (metaphysically) be in in $C$, that would well-equip $A$ to do the reason-demanded thing in $C$, then the putative demand lapses. This still seems true. And criticism of $A$ plainly is not apt in such cases. But suppose there is such a well-equipping condition, $X$, that $A$ could be in. What kind of a condition must $X$ be, specifically, such that its availability helps to make sense of the aptness of criticism (absent excuses), should $A$ still fail to do what the reasons demand?

It seems that $X$ must, at least, be some deliberative condition of $A$ 's. Consider: just as rocks or bugs are not subject to authoritative demands to behave in certain ways, nor are they aptly criticizable for failures to behave in those wayseven though there are conditions of rocks or bugs that well-equip them for certain behaviors in certain circumstances. (We can evaluate rocks as good or bad qua doorstops, say, but it makes little sense to demand them to perform better in

59 Not that some actual person must be able to appropriately level criticism, or some type of angry blame, at A if she fails to $\phi$; rather, criticism for failures to $\phi$ is in principle appropriate. Thanks to a referee for prompting me to clarify this.

60 As before, the relevant reasons are thus objective reasons in the sense of not being relative to A's information state (with some complications; cf. note 24 above). Do mistaken normative beliefs excuse? See Harman, "The Irrelevance of Moral Uncertainty," for illuminating discussion and a negative answer, regarding mistaken moral beliefs and excuses from moral blame in particular.

61 The example is from Sinclair, "Promotionalism, Motivationalism, and Reasons to Perform Physically Impossible Actions," 650-51. 
this regard, or to criticize them if they do not.) Likewise, very young infants are not aptly criticizable for failures to behave in certain ways, any more than they are subject to authoritative demands to behave in those ways. Nor are we, otherwise mature, thinking agents, aptly criticizable for having or failing to have involuntary, nonrational twitches. What we may be criticizable for is having done or failed to do, as an exercise of agency, something to cause such twitches. More generally, apt criticism attendant to failures to do the reason-demanded thing, $\phi$, concerns failures to $\phi$ under one's own steam, as an exercise of agency. Hence it seems that the well-equipping condition, $X$, whose availability helps to make sense of the aptness of criticism for failures to $\phi$, must be some broadly deliberative condition of $A$ 's: a condition in which $A$ acts via what is at least a minimally rational, as opposed to nonrational, response to features of the circumstance. Finally, though, $X$ cannot be just any old deliberative condition. Since $X$ must well-equip $A$ to do precisely the reason-demanded action in $C, X$ must somehow make $A$ sensitive to the reasons in $C$. Absent such a possible deliberative condition, the putative demands, along with the aptness of criticizing $A$ for failures to meet these demands, lapses.

So far I have argued that if some reasons, $p$, authoritatively demand of $A$ that she $\phi$ in $C$, then there must be some (a) deliberative condition, $X$, that $A$ could be in in $C$, that (b) well-equips $A$ to do, in $C$, precisely the reason-demanded action, by making $A$ somehow sensitive to the reasons in $C$. The question that remains is what deliberative condition $X$ best meets condition (b).

The obvious answer is: the condition of deliberating well, in light of all the reason-giving facts (along with enablers and disablers), where good deliberation in light of these facts involves weighing them correctly and being moved to do what the weightiest reasons support. It is certainly hard to see how deliberating badly — giving some facts inadequate or disproportionate weight in deliberation, or drawing bizarre conclusions from them-might well-equip, or better-equip, agents to do just what the facts in a situation demand of them. Likewise, it is hard to see how rational responses to misleading or irrelevant information, information that does nothing to support $\phi$-ing, would generally lead agents to $\phi{ }^{62}$ Such responses would seem, precisely, not to be sensitive to the reasons in the circumstance so as to well-equip $A$ to $\phi$. This is the key reason why RR is so plausible. RR is so plausible because responding to the reason-giving facts by weighing them accurately, and by being moved by the weightiest reasons to do what they support, is the best candidate deliberative condition to well-equip agents to meet the demands imposed by their reasons. 
I consider a major objection in section 5. For now, three important clarifications.

First, there may be stronger conditions on reasons than RR. I argued that, if reasons impose authoritative demands on $A$ to $\phi$, there must at least be a deliberative condition that $A$ metaphysically could be in, that would well-equip $A$ to meet those demands. Absent some such possible condition of $A$ 's, the putative demands on $A$ lapse. But while the relevant metaphysical possibility is necessary to ensure that reasons' demands do not lapse, perhaps it is insufficient. Specifically, if it is psychologically impossible for $A$ to be in the relevant deliberative condition, perhaps the reasons still lapse; correlatively, perhaps criticism given such psychological impossibility is inapt, not merely something that $A$ is excused from. Further, perhaps mere psychological possibility of being in the relevant deliberative condition is not enough to ensure that the reasons do not lapse, either. If the psychologically possible worlds in which $A$ is in the condition are very remote, then again it may seem dubious whether the reasons remain in force, and whether criticism for failures to abide by them is apt. (Compare criticizing someone for a failure to abide by a putative demand to swim across the English Channel, in pursuit of a large reward for a lifesaving charity, where a successful swim, while physically possible, is vanishingly unlikely.) This might motivate an even stronger, "internalist" constraint on reasons, on which $A$ 's reasons to $\phi$ depend on A's having the present actual motivational capacity to $\phi$ via rational sensitivity to those reasons. Having a present actual capacity to $\phi$ (e.g., swim, deliberate well) implies not just that one $\phi$ s in some possibly faraway world, but roughly, that there is a robust range of relatively nearby worlds in which one $\phi s$ (if one tries). ${ }^{63}$

Nothing I have said rules out such stricter constraints on reasons. Whether my argument can be positively extended to support them is a complex question I cannot adjudicate here. Still, if I am right, adjudicating it involves determining what kinds of impediment to exercising rational sensitivity to reasons merely excuse from otherwise reasonable criticism, leaving the reasons and their demands in place, and which impediments make the reasons lapse entirely. I doubt that there is a very neat way of deciding these questions. For instance, whether lack of present motivational capacity to $\phi$ via rational sensitivity to the reasons for $\phi$-ing even excuses failures to $\phi$ may depend on the cause of the lack. Vicious

${ }_{3}$ This is inexact, but suffices here. I consider motivational capacity claims, and the relevant kind of internalism, in more detail in Paakkunainen, "Internalism and Externalism about Reasons." Thanks to a referee and Benjamin Wald for prompting me to clarify my stance about these issues here. Cf. Lord, "Acting for the Right Reasons, Abilities, and Obligation," who argues for an epistemic and an ability condition on reasons-conditions that are also stronger than RR-on grounds somewhat similar to those I use to support RR. 
people may lack present motivational capacities to be moved by reasons to act well, but if they ought to have acquired such capacities and voluntarily did not, then perhaps the lack does not even excuse. ${ }^{64}$ All the same, my argument for RR stands. Whether or not stronger constraints can be supported on similar grounds, at the very least, RR is a condition of reasons' imposing authoritative demands. If $A$ metaphysically could not be in a deliberative condition that wellequips her to do the reason-demanded thing, $\phi$, the putative demand on $A$ to $\phi$ lapses. And the best candidate well-equipping deliberative condition, I argued, is that of deliberating well tout court à la RR.

The second clarification concerns the operative notions of authoritative demands, reasonable expectations, and apt criticism. We might worry that these notions are too obscure to guide our judgments in the area. For example, it is hard to precisely characterize the kind of criticism connected to failures to meet authoritative demands. Not all kinds of criticism are so connected: we sometimes seem to make "personal" criticisms of people for, e.g., having poor taste or for being boring, where such criticisms need not imply that their targets are under authoritative demands to be different, and likewise do not turn on the availability of some possible deliberative condition such that, if the agents were in it, they would be well-equipped to be less boring or to have better taste. But how can we assess my argument for RR without a better grip on the relevant notions and when they apply? Do we not first need a clear account of what it is for someone to be under authoritative demands, and of the attendant sort of criticism, in order to judge the merits of my argument? ${ }^{65}$

In response, I doubt we could first adequately characterize the operative notions, completely independent of their links to reasons and good deliberation, and then use them as precise criteria for assessing my argument for RR. If my argument works, it is because there is a cluster of concepts here that hang together, and whose interrelations help us, via reflection of the sort I engaged in, to clarify the contours of these very concepts - including the concept of a reason for action. Further, we can admit that criticism for other sorts of failures, apart from failures to do the reason-demanded thing, may be apt even absent the metaphysical possibility of avoiding the failure through good deliberation. Perhaps personal criticisms for being boring or having bad taste are like this; I am not sure. Still, as I argued, criticism attendant to failures for doing a reason-demanded action does seem to require, for its aptness, the relevant deliberative possibility. Like-

64 Thanks to Tristram McPherson for discussion.

65 Thanks to a referee for articulating this challenge. 
wise, unless criticism is apt for failures to do the reason-demanded thing (absent excuses), the putative demands seem to lapse. ${ }^{66}$

I cannot say much more than I have said to support the conceptual connections I have been tracing. Still, reflection on a different kind of normative fact concerning agent $A$, one that does not involve an authoritative demand on $A$, may help those skeptical of these connections. Suppose Alex ought to be amply rewarded. It is not that she ought to secure the reward for herself, and violates an authoritative demand on her if she does not. Rather, someone else ought to reward her. In such a case, it clearly does not follow that it is reasonable to expect of Alex that she be rewarded. It only seems reasonable to expect it of the person who ought to reward Alex. And if Alex is not rewarded, it seems inapt to criticize her for that; again, criticism is only apt for the person who ought to reward Alex. Likewise, there need be no possible deliberative condition of Alex's that would well-equip her to secure the reward in the situation. Perhaps it is simply not up to Alex whether she gets rewarded, no matter how well she deliberates. Finally, whatever makes the claim "Alex ought to be amply rewarded" true (in context), it seems clear that it is not something about Alex's (present) normative reasons for action. (Though it may involve Alex's having done something she previously had good reason to do. $)^{67}$

So it seems that ought-facts concerning $A$ that do not imply an authoritative demand on $A$ likewise are not linked to what $A$ could be reasonably expected to do, would be aptly criticizable for, or could do through a course of good deliberation; nor are they linked to A's reasons for action. I think it is no accident that these verdicts cluster in this way-as they seemed to cluster in the positive case where A's reasons do impose authoritative demands on her. These appearances are some further confirmation that the links drawn between reasons, authoritative demands, reasonable expectations, apt criticism, and good deliberation trace important joints in our normative concepts.

Finally, the third clarification concerns the requirement that, where A's reasons demand her to $\phi$, it must be that $A$ herself could deliberate to the conclusion to $\phi$, via sensitivity to her reasons. Why is it not enough if someone else-a trusted advisor-deliberates on A's behalf, telling $A$ that she ought to $\phi$, though

66 A slightly different challenge in the vicinity is that we need at least some sense of the operative notions of authoritative demands and apt criticism, even if not a clear account, to judge the merits of my argument. But again, the reflections in this section trade on, as well as serve to clarify, such a sense. The example is adapted from Broome, Rationality through Reasoning, 65. 
keeping the reasons why hidden from $A$ ? Better still, perhaps the mere possibility of such a trusted advisor, and of shared deliberative labor, is enough ${ }^{68}$

Here is why this does not work. Suppose the advisor is actually present, but gets it wrong, telling $A$ to $\psi$ instead of to $\phi$. If it is not even metaphysically possible for $A$ herself to better deliberate to the right conclusion, then it seems that, again, $A$ cannot be aptly criticized for failing to $\phi$, and the putative demand on $A$ to $\phi$ seems to lapse. (This is perhaps clearest where $A$ had decisive reasons to trust the advisor.) The mere possibility of an advisor who gets it right does not seem to change this verdict. But what if the actual advisor gets it right? Perhaps at least in such cases it need not be that $A$ could herself deliberate well to the conclusion to $\phi$ ? But it would be odd for the presence or absence of $A$ 's reasons to $\phi$ to depend on the serendipitous presence of an actual advisor who gets her advice right. Note that the converse judgment does not seem plausible: if it were for some reason metaphysically impossible for $A$ to have a trusted advisor of the relevant sort, but $A$ herself had (perhaps serendipitously) a generally excellent, though not infallible, sensitivity to reasons, we would not thereby think that reasons cannot impose demands on $A$ (even where $A$ in fact gets it wrong).

Shared deliberative labor can happen, and is sometimes useful. Outsourcing deliberative labor to experts often minimizes our risk of going wrong. Still, if we metaphysically could not have gotten it right ourselves, and the experts lead us astray, reasons cannot demand us to $\phi$. And the presence of reasons for us to $\phi$ does not depend on whether an actual expert accurately tracks them on our behalf. ${ }^{69}$

\section{INDIRECTION RECONSIDERED}

Suppose I am right that, if reasons demand $\phi$-ing of $A$ in a situation, then there is a possible deliberative condition of $A$ 's that well-equips $A$ to do precisely the demanded action in that situation. We might nonetheless doubt my further claim that the best candidate deliberative condition is that of deliberating well tout court-responding rationally to the reason-giving and other relevant facts, by weighing them accurately and being moved by the weightiest reasons to do what they demand. We might doubt this claim for reasons similar to those fueling government house or "indirect" utilitarianism.

68 Thanks to a referee for raising this concern. Cf. Sinclair, "On the Connection between Normative Reasons and the Possibility of Acting for those Reasons."

69 A more complete treatment would discuss cases such as Sinclair's Tate/Loco case ("On the Connection between Normative Reasons and the Possibility of Acting for those Reasons," 1220), but I cannot do that here. 
Recall the key thought behind indirect utilitarianism: while agents morally ought to maximize utility, they are more likely to do so if their deliberations ignore considerations about impartial utility-maximization, and focus on ordinary considerations of, e.g., friendship, personal loyalty, or love. For utility calculations are hard and often take too long for actual agents to complete before action is required. Further, always focusing on impartial utility considerations would deprive agents of personal attachments that themselves have significant utility. One cannot really love a person if this person and their specific concerns never weighs more heavily in one's deliberations than the concerns of strangers. Finally, and related: even if impartial utility calculations allowed agents to weight their loved ones' interests more heavily than the interests of strangers-perhaps because special bonds between people contribute heavily to utility, and each agent is best positioned to maintain their own special bonds-we might still worry that, if loved ones' concerns are given special weight in deliberation only because doing so is utility-maximizing, or under the guise of utility-maximization, this again is incompatible with real love, the very thing whose contribution to utility we are concerned to preserve. ${ }^{70}$

We might raise similar concerns about deliberating in terms of the reason-giving facts. ${ }^{71}$ First, taking account of all the reason-giving facts-even the important ones-is sometimes too hard or takes too long. Perhaps shortcuts or rule-ofthumb policies of deliberation often better-equip actual agents to do what their reasons demand than does attempting to take account of the reason-giving facts à la RR. (Perhaps such policies provide a kind of indirect sensitivity to reasons' demands.) Second, agents often have reasons to act in loving, kind, loyal, modest, etc., ways; indeed, plausibly the very fact that $\phi$-ing would be loving, kind, etc., is itself a reason, and an important one, to $\phi$. After all, being loving, kind, etc., are important good-making features of acts, and plausibly, important good-making features of acts provide reasons to perform those acts. Yet (so the objection goes) $\phi$-ing is an act of love, kindness, etc., only if, in $\phi$-ing, one does not act on the consideration that $\phi$-ing is an act of love or kindness. Acts of love or kindness are motivated by direct concerns for loved ones' interests, or for others' needs: concerns not mediated by a further concern with whether the actions would express positive characteristics in oneself. In short, the second concern is that, while the fact that $\phi$-ing would be an act of (say) love or kindness is a reason to

70 For classic discussion, see, e.g., Williams, Ethics and the Limits of Philosophy, 107-10; Railton, "Alienation, Consequentialism, and the Demands of Morality" and "How Thinking about Character and Utilitarianism Might Lead to Rethinking the Character of Utilitarianism."

71 I will not worry about keeping the concerns below exactly parallel to those raised above. I will simply try to raise the best objections in the vicinity. 
$\phi$, this fact, and so the reason, would be destroyed if it were among the considerations that move one to act. ${ }^{72}$

I address the two concerns in order. The second one motivates small qualifications to RR, but these are independently well motivated, and preserve the core thought in RR and my argument for it.

As noted in sections 1-2, imperfect agents may do well to rely on rule-ofthumb policies when they are unlikely to respond rationally to considering the reason-giving facts, perhaps due to getting unnerved. This does not conflict with RR. However, the present objection is not that the usefulness of rule-of-thumb policies conflicts with RR. It is rather that the argument for RR in section 4 misfires, given the usefulness of such policies. That argument claimed that responding rationally to the reason-giving facts-via direct sensitivity to them, à la RRis the best candidate deliberative condition to well-equip $A$ to meet her reasons' demands. The present objection is that it is not: often the best deliberative condition to well-equip agents to do reason-demanded actions is that of applying rule-of-thumb policies that ignore the reason-giving facts. Such policies often better lead imperfect agents to doing what they ought than does attempting to deliberate well tout court, in ways they are unlikely to succeed in doing.

This objection is ultimately confused. The argument of section 4 turns on identifying the deliberative condition that would best equip agents to do what their reasons demand in a situation, were they to be in that condition. The condition of deliberating well tout court, where this involves weighing reasons accurately and being moved by the weightiest reasons to do what they support, still seems like the best candidate. Following rules of thumb may indeed often better lead imperfect agents to doing what they ought than would attempting to deliberate well tout court. But if so, this is because these agents' imperfections make them unlikely to deliberate well tout court in the situation at hand. This is compatible with holding that, were these agents to deliberate well tout court in their situation, they would be even better equipped to meet the demands of the situation. $^{73}$

Thanks to Massimo Renzo and a referee for formulating versions of these objections especially clearly. The second objection resembles Surprise Party or James Bond, except that, in those cases, mere belief that $p$ is supposed to destroy $p$ 's status as a reason (perhaps by destroying $p$ 's status as a fact). In the present objection, $A$ might perhaps believe that $\phi$-ing would be an act of (say) love, and still perform $\phi$-ing out of love. But the fact that $\phi$-ing would be an act of love allegedly cannot be among the considerations on which one acts, without destroying the act's status as an act of love, thereby destroying the reason. A's reasons depend; for it would thereby destroy the supposed reasons. But disappearing the imperfections that prevent $A$ from undertaking a particular course of good deliberation 
This point may seem merely nitpicky, but its force is evident where rules of thumb lead astray. Indirect utilitarians readily admit that rules of thumb can lead astray. Deliberating on the basis of, say, considerations of love or loyalty may often maximize utility, but sometimes it will not. ${ }^{74}$ Similar scenarios can arise for reasons and the rule-of-thumb policies of deliberation that ignore them-as with the soldier who ignores the common humanity of the enemy inhabitants even when it is relevant to which combat maneuvers to perform. Where rules of thumb do lead astray, following them plainly is not the deliberative condition that best equips you to do what you ought. If you follow a rule of thumb accurately when it leads you astray, you precisely will not do what you ought. You might still accidentally end up doing what you ought if you follow the rule of thumb badly, or if you do not deliberate at all and simply act on the basis of no considerations whatsoever. But neither of these latter strategies plausibly better equips you to do what you ought than does deliberating well tout court.

Hence following rule-of-thumb policies cannot be the best candidate deliberative condition, across the board, to well-equip agents to meet their reasons' demands. The best candidate deliberative condition still seems to be deliberating well tout court. In response, one might propose a disjunctive condition on reasons: there must be either a rule-of-thumb policy that ignores one's reasons, or a deliberative route that takes them into account à la RR. This would leave room for $\mathrm{GH}$ reasons. But, as always, a more unified view is preferable if it has no significant costs. So far RR seems to have no significant costs: neither Surprise Party-style cases nor Soldier-type cases turned up such costs (section 2). We should prefer the simple and natural view that reasons relate to good deliberation directly, as premises to be weighed and acted upon, to disjunctive views that have no clear benefit.

However, perhaps the second concern above, regarding acts of love, kindness, etc., motivates a disjunctive view. Facts such as that $\phi$-ing would be kind or loving do seem to be reasons-indeed, often decisive ones— to $\phi$. Denying

need not destroy the imperfections on which the relevant reasons depend. Take the famous "sore loser" example (Smith, "Internal Reasons," 111-12; Watson, "Free Agency"): A's intemperance gives her reasons to avoid shaking her winning opponent's hand, reasons that a more temperate version of $A$ would lack. Still, there can be a course of good deliberation that takes into account $A$ 's actual intemperate self's reasons in the situation, weighs them accurately and leads to A's being moved by the weightiest reasons to do what they support. This course of deliberation, like the reasons it registers, differs from the course of good deliberation that $A$ 's more temperate counterpart would engage in.

74 See, e.g., Railton, "Alienation, Consequentialism, and the Demands of Morality," 157, and "How Thinking about Character and Utilitarianism Might Lead to Rethinking the Character of Utilitarianism," 402. 
that they are reasons seems to carry a higher intuitive cost than denying that, e.g., the specific fact that a surprise party awaits—instead of some other, nearby fact, such as that Nate would be glad if he went home-is a reason for Nate go home. Yet it seems that deliberating well tout court is not an option in these cases, compatibly with the reasons remaining on the scene. This may be the strongest intuitive challenge to $\mathrm{RR}$, in the vicinity of Surprise Party-style cases.

I will make two main points in response. First, it seems that one can act in, e.g., a loving way while basing one's act, at least partly, on the fact that the act would be loving. We often try to figure out what "the loving thing to do" would be, whether in our own case or when advising others. And when an advisor gives advice in this regard, we would not naturally expect them to immediately also advise us to forget the advice. We understand an action's being the loving thing to do as a significant reason in its favor, and one that is not to be ignored. Admittedly, it is doubtful that an act would really be loving if its being loving were the only consideration the agent took into account. It seems that those performing genuinely loving acts also have some grasp of why the act would be loving, and they act partly on these further considerations. Still, it seems that one can act lovingly while having "this is the loving thing to do" figure as a summary judgment in one's deliberations, summing up the kind of importance that various other facts of the case, the facts that make the act a loving one, have.

Likewise for kindness, and even modesty. It seems that actions can be modest while being based, partly, on the fact that this is "the modest thing to do," or that "doing otherwise would be immodest." Recall that taking such considerations into account can be swift, as it plausibly is in genuinely modest people. Taking them into account does not require self-congratulatory lingering on thoughts about how modest one is about to be. It is such self-congratulatory lingering that seems modesty-undermining in these cases, not the swift registering of the fact that this is the modest thing to do. Deliberation preceding modest, loving, or kind acts plausibly spends most time focused on other considerations. Nor will modest, loving, or kind agents try to draw others' attention to the good qualities of themselves or their actions. ${ }^{75}$ But this is compatible with basing one's action partly on the consideration that it is the modest, kind, or loving thing to do.

This defuses much of the objection involving loving, kind, modest, etc., actions, but not all of it. We previously claimed that good deliberation takes account of all the important reasons, lest it lead agents astray from what the balance of reasons supports (section 1). Yet one can act in loving, kind, modest

75 Compare Star's helpful discussion of modesty, on which I partly draw; though I am unsure he would grant that acting on the consideration that "this is the modest thing to do" is compatible with the act's modesty (Knowing Better, 83-85). 
ways without considering the act's status as loving, kind, or modest; indeed, the paradigm cases of loving, kind, modest actions are like this. And surely deliberation that ignores the fact that the action would be (say) loving is not faulty for that - and need not risk leading the loving agent astray. If so, and if the fact that $\phi$-ing would be loving is an important reason to $\phi$, then RR must be qualified.

This brings me to the second main point of response. When an act is, say, loving or kind, further features of the act make it so. Perhaps the act serves a loved one's or a stranger's needs, say. These further features seem to also provide reasons to perform the relevant acts. But crucially, the two sets of considerationsone about others' needs, the other about the act's being loving or kind-do not constitute two independent normative cases in favor of the act. Consider: if acting lovingly or kindly somehow involved trampling others' needs, then an act's being loving or kind would not seem like much of a mark in its favor. Much of the normative import of an act's being loving or kind seems bound up with the normative import of others' needs. ${ }^{76}$ "Bound up" how? I will describe two options, independently well motivated, each of which seems to be actualized in some cases. We need not decide which option better fits cases of loving/kind actions. The key point is that each option fits a slightly modified RR, while preserving the spirit of the argument for RR.

Option 1: Reasons are not individual, fine-grained facts, but clusters of facts. Context determines which facts in the cluster it is most natural for agents to consider in deliberation. (Or to give as advice, or as explanations of actions after deliberation.) Often when one fact is identified as a reason for $A$ to $\phi$, many nearby facts look like equally good candidate reasons for $A$ to $\phi$-indeed, reasons of equal strength. Yet we should not count all of these facts as reasons separately: that would yield a cumulative case for $\phi$-ing that is too strong. If I ought to visit my mother soon, we might cite the decisive reason as the fact that she is sick, or that she has pneumonia, or that, being sick, she will need some care. These do not each add independent weight to the case for visiting my mother. Yet each is a good candidate reason, and it is unclear how to choose which "the" reason is. Further, it is a rational response to each of these facts for me to go visit my mother: each candidate reason corresponds to a good deliberative route. This phenomenon seems extremely common. This is why it is natural to view reasons as clusters of facts, where context determines - with some room for arbitrariness - which individual facts get called "the reasons" in the situation, and get to be the focus in deliberation. ${ }^{77}$

While this seems less plausible to me, we might also doubt the normative import of facts about others' needs if tending to them were somehow systematically unloving or unkind. 
Applying this idea to loving/kind actions, the fact that an act is (say) loving and the facts that make it loving belong to a cluster of facts that collectively call for specific actions. Depending on context, only some of these facts are the focus of a given course of good deliberation, or of advice. We can modify RR to accommodate these points. What is important is that, given decisive reasons to $\phi$ - whichever facts get called "the reasons" in the context-a good deliberative route takes you from considering these reasons to $\phi$-ing. The core thought in the argument for RR remains: the best deliberative condition to well-equip agents to do what their reasons demand is to take account of key facts in the relevant cluster, weighting them accurately and doing what they (together with other facts in the cluster) demand. This still differs crucially from deliberation that focuses on non-reason-giving considerations; yet it explains why, with loving/kind actions, we can deliberate well without considering the specific fact that these actions are loving or kind.

Option 2 (not really in tension with the "cluster" idea but going beyond it): Some reasons are normatively fundamental, while others derive their normative import from the fundamental reasons. Suppose $\phi$-ing would destroy the only crop-yielding field in a village, and destroying this field would lead to much suffering. Both facts seem to be reasons-indeed, decisive ones-against $\phi$-ing. But the status of the first fact as a reason against $\phi$-ing seems derivative from the status of second fact, about suffering, as a reason against $\phi$-ing. The second fact is more fundamental as a reason, while the first fact is a derivative one: it is a reason because destroying the field would cause much suffering. ${ }^{78}$ Here, a rational response to either the derivative or the (more) fundamental reasons would lead you to do what the balance of reasons supports. We should construe RR so that each counts as a good deliberative route. Where neither rational focus on solely the derivative reasons nor rational focus on solely the fundamental reasons would lead you astray from what you ought to do, good deliberation can safely focus on just one or another set of reasons. (And deliberation that does consider both sets of reasons should not count each set as independently weighty, on pain of overestimating the case against $\phi$-ing.)

Applying this idea to loving/kind actions, some of the reasons in the case are derivative, others fundamental. (We need not decide which are which.) Where a rational response to either the fact that the act is loving/kind, or to the facts that make the act loving/kind, would lead to doing what the balance of reasons

see Raz, From Normativity to Responsibility, 16-17.

78 See Star, Knowing Better, for a thorough discussion of fundamental versus derivative reasons. Star argues that his theory of reasons to $\phi$ as evidence that one ought to $\phi$ accommodates this phenomenon well. 
supports, you can safely focus on just one set of facts while ignoring the other. The core thought in RR is that there must be a possible rational response to the important reasons in a situation that would lead you from considering those reasons to doing what the reasons demand of you. This core thought is preserved even if we acknowledge that there is leeway, because of dependency relations between reasons, as to which of them good deliberation focuses on.

I have argued that we can allow that an act's being, say, loving or kind is an important reason in its favor. One can act lovingly or kindly while taking these reasons into account. One can also act lovingly or kindly without taking these reasons into account, but this does not threaten RR or my argument for it either-not once we qualify RR in certain independently well motivated ways. Finally, the usefulness of rule-of-thumb policies of deliberation does not undermine my argument either. ${ }^{79}$ The most pressing objections inspired by indirect utilitarianism fail. RR and my argument for it stand.

\section{CONCLUSION}

A version of the Deliberative Constraint holds because without it, we cannot make sense of the peculiar normativity of reasons for action: of their ability, when decisive, to impose authoritative demands on agents. I defended RR, with some qualifications, as a good formulation of the Deliberative Constraint. I grant that a different reason-concept, one that abandons RR, might play other important theoretical roles, even if it cannot play the roles associated with reasons' peculiar normativity. Indeed, for all I have said, there may be important theoretical roles that reasons that obey RR cannot play. I am unaware of any such roles. Reasons' role in giving and receiving advice, for example, or in explaining normatively well-supported action, seem compatible with RR. Still, this is territory ripe for further exploration. My view is that we should be as clear as possible about which theoretical and related everyday roles various notions can and cannot play, and subsequently about where to draw principled lines between importantly different reason-concepts. ${ }^{80}$

Despite its modesty, RR does have implications for further theorizing. First, since the Advice Model of reasons is compatible with the falsity of RR, that model is either false (if unsupplemented by RR) or incomplete-at least, as a model

79 Note further that given the distinction between fundamental and derivative reasons, it is somewhat plausible that rule-of-thumb policies work, to the extent that they do, by taking account of (what are in most cases) derivative reasons, even if they ignore the fundamental ones. However, I will not pursue this here.

Thanks to David Plunkett and Daniel Star for helpful discussion here. 
of reasons capable of imposing authoritative demands on the agents whose reasons they are. ${ }^{81}$ Likewise for other views that do not incorporate a commitment to RR. Second, evaluative facts about good deliberation constrain facts about reasons, and we may find first-order normative insight, as well as metaethical insight about how reasons function, by studying good practical reasoning. Third, metaphysical facts about what deliberation as such can be like also constrain facts about reasons, via constraining facts about what good deliberation can be like. This makes the study of agency necessary for understanding reasons. Finally, theories that explain why RR holds are preferable to theories that do not. RR is a key explanandum for theorists of reasons, good reasoning, and agency. It should be explicitly in the foreground as a guide to theorizing. ${ }^{82}$

I have only addressed reasons for action. Does some analogue of the Deliberative Constraint apply to reasons for belief or emotion, and does my argument extend to these cases? While I doubt that a similar argument will extend to these cases, there may be different arguments for epistemic or emotional analogues of the Constraint. ${ }^{83}$ This is a further area ripe for exploration. ${ }^{84}$

Syracuse University hpaakkun@syr.edu

81 Cf. Smith, "Internal Reasons" and "Reasons with Rationalism after All"; and my introduction, above. Note that RR is importantly distinct from the "Example Model" that is Smith's foil in defending the Advice Model. Unlike the Example Model, RR treats agents' imperfections in a way designed not to eliminate reasons that depend on those very imperfections. See notes 24, 38, 46, and 73 above for some relevant remarks.

82 In the way that, e.g., Setiya (Reasons without Rationalism and "What Is a Reason to Act?") and Way ("Reasons as Premises of Good Reasoning") foreground their versions of the Deliberative Constraint.

83 See, e.g., Hieronymi's "The Wrong Kind of Reason" and "The Use of Reasons in Thought (and the Use of Earmarks in Arguments)" for an argument that thinking of reasons as premises in reasoning helps to distinguish right from wrong kinds of reasons for attitudes.

84 For extremely helpful feedback on previous versions of this material, I am grateful to the participants of the 2015 NYU Abu Dhabi Workshop on Normativity and Reasoning, the participants of the 2015 CEPA Seminar at the Murphy Institute at Tulane University, the participants of the 2015 St. Louis Annual Conference on Reasons and Rationality, referees for this and one other journal, and especially to Samuel Asarnow, Daniel Fogal, Kim Frost, André Gallois, Tristram McPherson, David Plunkett, Massimo Renzo, Mark Schroeder, Oliver Sensen, Neil Sinhababu, Daniel Star, Sergio Tenenbaum, Benjamin Wald, Jonathan Way, and Ralph Wedgwood. I am grateful to the Center for Ethics and Public Affairs at the Murphy Institute at Tulane for supporting part of the work for this paper. 


\section{REFERENCES}

Ashwell, Lauren. "Superficial Dispositionalism." Australasian Journal of Philosophy 88, no. 4 (December 2010): 635-53.

Broome, John. Rationality through Reasoning. Oxford: Oxford University Press, 2013.

Chang, Ruth. "Introduction." In Incommensurability, Incomparability, and Practical Reason, edited by Ruth Chang, 1-34. Cambridge, MA: Harvard University Press, 1997.

Clarke, Randolph. "Opposing Powers." Philosophical Studies 149, no. 2 (June 2010): 153-60.

Copp, David. "Moral Naturalism and Three Grades of Normativity." In Morality in a Natural World, 249-83. Cambridge: Cambridge University Press, 2007.

—_ "Toward a Pluralist and Teleological Theory of Normativity." Philosophical Issues 19, no. 1 (October 2009): 21-37.

Dancy, Jonathan. Ethics without Principles. Oxford: Oxford University Press, 2004.

_- "Nonnaturalism." In Oxford Handbook of Ethical Theory, edited by David Copp, 122-43. New York: Oxford University Press, 2006.

Darwall, Stephen. Impartial Reason. Ithaca, NY: Cornell University Press, 1983.

Enoch, David. "Agency, Shmagency: Why Normativity Won't Come from What Is Constitutive of Action." Philosophical Review 115, no. 2 (April 2006): 169-198.

- Taking Morality Seriously: A Defense of Robust Realism. Oxford: Oxford University Press, 2011.

Finlay, Stephen. "Recent Work on Normativity." Analysis 70, no. 2 (April 2010): 331-46.

FitzPatrick, William. "Robust Ethical Realism, Non-Naturalism, and Normativity." Oxford Studies in Metaethics 3 (2008): 159-206.

Foot, Philippa. Natural Goodness. Oxford: Oxford University Press, 2001.

Gert, Joshua. "Requiring and Justifying: Two Dimensions of Normative Strength." Erkenntnis 59, no. 1 (July 2003): 5-36.

Handfield, Toby, and Alexander Bird. "Dispositions, Rules, and Finks." Philosophical Studies 140, no. 2 (August 2008): 285-98.

Harman, Elizabeth. "The Irrelevance of Moral Uncertainty." Oxford Studies in Metaethics 10 (2010): 53-79.

Hieronymi, Pamela. "The Use of Reasons in Thought (and the Use of Earmarks in Arguments)." Ethics 124, no. 1 (October 2013): 114-27. 
—. "The Wrong Kind of Reason." Journal of Philosophy 102, no. 9 (September 2005): 437-57.

Horty, John F. Reasons as Defaults. Oxford: Oxford University Press, 2012.

Johnson, Robert N. "Internal Reasons and the Conditional Fallacy." The Philosophical Quarterly 49, no. 194 (January 1999): 53-71.

_ . "Internal Reasons: Reply to Brady, Van Roojen, and Gert." The Philosophical Quarterly 53, no. 213 (October 2003): 573-80.

Korsgaard, Christine M. Self-Constitution: Agency, Identity, and Integrity. Oxford: Oxford University Press, 2009.

- "Skepticism about Practical Reason." The Journal of Philosophy 83 no. 1 (January 1986): 5-25.

. The Sources of Normativity. Cambridge: Cambridge University Press, 1996.

Lord, Errol. "Acting for the Right Reasons, Abilities, and Obligation." Oxford Studies in Metaethics 10 (2015): 26-52.

Lord, Errol, and David Plunkett. "Reasons Internalism." In The Routledge Handbook of Metaethics, edited by David Plunkett and Tristram McPherson. Abingdon: Routledge, 2017.

Manne, Kate. "Internalism about Reasons: Sad but True?" Philosophical Studies 167, no. 1 (January 2014): 89-117.

Markovits, Julia. Moral Reason. Oxford: Oxford University Press, 2014.

McDowell, John. "Might There Be External Reasons?” In World, Mind, and Ethics, edited by J. E. J. Altham and Ross Harrison, 68-85. Cambridge: Cambridge University Press, 1995.

McPherson, Tristram. "Against Quietist Normative Realism." Philosophical Studies 154, no. 2 (June 2011): 223-40.

Millgram, Elijah. "Williams' Argument Against External Reasons." Noûs 30, no. 2 (June 1996): 197-220.

Paakkunainen, Hille. "Internalism and Externalism about Reasons." In The $O x$ ford Handbook of Reasons and Normativity, edited by Daniel Star. Oxford: Oxford University Press, forthcoming.

- "Normativity and Agency." In The Routledge Handbook of Metaethics, edited by David Plunkett and Tristram McPherson. Abingdon: Routledge, 2017. Parfit, Derek. On What Matters. 2 vols. Oxford: Oxford University Press, 2011.

Portmore, Douglas W. Commonsense Consequentialism: Wherein Morality Meets Rationality. Oxford: Oxford University Press, 2011.

Railton, Peter. "Alienation, Consequentialism, and the Demands of Morality." Philosophy and Public Affairs 13, no. 2 (Spring 1984): 134-71.

- "How Thinking about Character and Utilitarianism Might Lead to Re- 
thinking the Character of Utilitarianism." Midwest Studies in Philosophy 13, no. 1 (September 1988): 398-416.

Raz, Joseph. From Normativity to Responsibility. Oxford: Oxford University Press, 2011.

- ed. Practical Reasoning. Oxford: Oxford University Press, 1978.

- "The Truth in Particularism." In Engaging Reason: On the Theory of Value and Action, 218-46. Oxford: Oxford University Press, 1999.

Scanlon, Thomas M. Being Realistic about Reasons. Oxford: Oxford University Press, 2014.

Schroeder, Mark. "Realism and Reduction: The Quest for Robustness." Philosophers' Imprint 5, no. 1 (February 2005): 1-18.

- Slaves of the Passions. Oxford: Oxford University Press, 2007.

Setiya, Kieran. "Introduction: Internal Reasons." In Internal Reasons: Contemporary Readings, edited by Kieran Setiya and Hille Paakkunainen. Cambridge, MA: MIT Press, 2012.

- Reasons without Rationalism. Princeton, NJ: Princeton University Press, 2007.

—. "Reply to Bratman and Smith." Analysis 69, no. 3 (July 2009): 531-40.

. "What Is a Reason to Act?" Philosophical Studies 167, no. 2 (January 2014): 221-35.

Setiya, Kieran, and Hille Paakkunainen, eds. Internal Reasons: Contemporary Readings. Cambridge, MA: MIT Press, 2012.

Shafer-Landau, Russ. "A Defence of Categorical Reasons." Proceedings of the Aristotelian Society 109, no. 1 (August 2009): 189-206.

Sinclair, Neil. "On the Connection between Normative Reasons and the Possibility of Acting for those Reasons." Ethical Theory and Moral Practice 19, no. 5 (November 2016): 1211-23.

—. "Promotionalism, Motivationalism, and Reasons to Perform Physically Impossible Actions." Ethical Theory and Moral Practice 15, no. 5 (November 2012): 647-59.

Skorupski, John. The Domain of Reasons. Oxford: Oxford University Press, 2010. Smith, Michael. "Internal Reasons." Philosophy and Phenomenological Research 55, no. 1 (March 1995): 109-31.

- The Moral Problem. Malden, MA: Blackwell Publishing, 1994.

. "Reasons with Rationalism After All." Analysis 69, no. 3 (July 2009): 521-30.

Sobel, David. "Explanation, Internalism, and Reasons for Action." Social Philosophy and Policy 18, no. 2 (Summer 2001): 218-35. 
. Review of Slaves of the Passions, by Mark Schroeder. Notre Dame Philosophical Reviews (2009). http://ndpr.nd.edu/news/slaves-of-the-passions.

Star, Daniel. Knowing Better: Virtue, Deliberation, and Normative Ethics. Oxford: Oxford University Press, 2015.

Sturgeon, Nicholas L. "Ethical Naturalism." In Oxford Handbook of Ethical Theory, edited by David Copp, 91-121. New York: Oxford University Press, 2006.

Wallace, R. Jay. "Constructivism about Normativity: Some Pitfalls." In Constructivism in Practical Philosophy, edited by James Lenman and Yonatan Shemmer, 18-39. Oxford: Oxford University Press, 2012.

Watson, Gary. "Free Agency." The Journal of Philosophy 72, no. 8 (April 1975): 205-20.

Way, Jonathan. "Reasons as Premises of Good Reasoning." Pacific Philosophical Quarterly 98, no. 2 (June 2017): 1-20.

Williams, Bernard. Ethics and the Limits of Philosophy. London: Fontana Press, 1985.

. "Internal and External Reasons." In Moral Luck, 20-39. Cambridge: Cambridge University Press, 1981. 